\title{
CURADORIA DE SENTIDOS EM MULTILETRAMENTOS DIGITAIS NO CURSO DE LETRAS INGLÊS DA UNIVERSIDADE FEDERAL DO ACRE ${ }^{1}$
}

\author{
SENSE CURATION IN DIGITAL MULTILITERACIES IN ENGLISH LANGUAGE AND \\ LITERATURE TEACHING COURSE AT THE FEDERAL UNIVERSITY OF ACRE
}

\author{
Aline Kieling* \\ Paula Tatiana Silva-Antunes* \\ Gabriela Oliveira-Codinhoto***
}

\section{RESUMO}

As práticas discursivas na contemporaneidade constituem-se de relações dialógicas cada vez mais inter/multi/transculturais e multissemióticas devido aos processos de globalização e, sobretudo, pelos avanços das Tecnologias Digitais da Informação e Comunicação (TDIC). Desse modo, emergem outros (multi)letramentos. No entanto, há ainda diversas lacunas que inviabilizam espaços de (multi)letramentos na educação formal do Brasil, entre elas a formação de professores. Nesse sentido, o objetivo desta pesquisa é avaliar em que medida o Projeto Político Curricular (PPC) do curso de Letras Inglês da Universidade Federal do Acre (UFAC), campus Floresta, possibilita (ou não) aos discentes o desenvolvimento da curadoria de sentidos em (multi) letramentos digitais, de maneira crítica, ética e estética para a prática docente. Para isso, sob a ótica da Linguística Aplicada in/ transdisciplinar (MOITA LOPES, 2006; ROJO, 2006), avaliamos sete excertos do PPC em foco, relacionados às TDIC. Por meio das análises, de cunho qualitativo, constatamos que a curadoria de sentidos em (multi)letramentos digitais está presente na política de formação de professores do referido curso de Letras, entretanto; as ementas das disciplinas relacionadas aos gêneros discursivos do campo acadêmico e do campo artístico-literário são incipientes às demandas das práticas discursivas emergentes. Palavras-chave: multiletramentos; TDIC; formação de professores; Curso de Letras-Inglês.

\section{ABSTRACT}

Contemporary discursive practices are constituted by increasingly inter/multi/transcultural and multisemiotic dialogic relations due to the processes of globalization and, above all, by the advances in digital Information and Communication Technologies. In this context, other (multi) literacies emerge. On the other hand, there are still several gaps that preclude spaces for (multi)literacies in formal education in Brazil, including teacher education. In this sense, the aim of this research is to evaluate to what extent the "Curriculum" [Projeto Político Curricular - PPC] of the undergraduate course in English Language and Literature Teaching [Letras Inglês] at the Federal University of Acre [Universidade Federal do Acre - UFAC], campus Floresta, allows (or not) the development of sense "curation" in digital multiliteracies, in the critical, ethical, and aesthetic ways of English Language Teaching (ELT) practice. In order to do so, from the perspective of in/transdisciplinary Applied Linguistics (MOITA LOPES, 2006; ROJO, 2006), we evaluated seven excerpts of the PPC in focus, related to Digital Technologies. Through qualitative analysis, we found that the sense "curation" in digital multiliteracies is present in the teacher education policies of the mentioned course; however, summaries of disciplines related to speech genres from academic and artistic-literary fields are incipient to the demands of emerging discursive practices.

Keywords: multiliteracies; digital technologies; teacher education; English Language and Literature Teaching Course.

\section{INTRODUÇÃO}

Em contextos contemporâneos da "modernidade tardia" (HALL, 1997), os discursos se constituem por processos dialógicos de enunciação (BAKHTIN, [1952-53] 2016) cada vez mais inter/multi/transculturais e multissemióticos (ROJO, 2012; THE NEW LONDON GROUP, 1996) a partir da conexão em rede no "ciberespaço" e da "linguagem hipermídia" (SANTAELLA, 2004).

Emergem, então, outros (multi)letramentos pelas formas hipermidiáticas de se relacionar com os discursos e de (re)significá-los. Isso demanda não apenas "[...] o domínio de ferramentas de edição de foto, de áudio [...], de vídeo [...], [de texto escrito]" (ROJO e BARBOSA, 2015, p. 123) e de outros conhecimentos acerca do bardware e

* Doutoranda do Programa de Pós-Graduação em Letras: Linguagem e Identidade na Universidade Federal do Acre (UFAC), Rio Branco, Acre, Brasil. e bolsista CAPES. aline.kieling@sou.ufac.br.

Orcid: https://orcid.org/0000-0002-5993-5834. Lattes: http://lattes.cnpq.br/8538704564185190

** Universidade Federal do Acre, Ufac, Rio Branco, AC, Brasil. paula.antunes@ufac.br.

Orcid: https://orcid.org/0000-0002-7372-8153. Lattes: http://lattes.cnpq.br/1352340622537872

***Universidade Federal do Acre, Ufac, Rio Branco, AC, Brasil. gabriela.codinhoto@ufac.br.

Orcid: https://orcid.org/0000-0003-0883-0984. Lattes: http://lattes.cnpq.br/3546169566859489

1. O presente trabalho foi realizado com apoio da Coordenação de Aperfeiçoamento de Pessoal de Nível Superior - Brasil (CAPES) - Código de Financiamento 001 
do software, mas também da curadoria de sentidos (ROJO e BARBOSA, 2015), ou seja, a capacidade para escolher, selecionar, organizar e expressar conteúdos/discursos no "ciberespaço" (SANTAELLA, 2004) de maneira crítica, ética e estética. Segundo Rojo e Barbosa, o conceito de curadoria, proveniente do campo artístico, tem sido

cada vez mais usado para designar ações e processos próprios do universo das redes: tanto conteúdo e tanta informação abundantes, dispersos, difusos, complementares e/ou contraditórios e passíveis de múltiplas interpretações, precisam de reordenamentos que os tornem inteligíveis e/ou que revistam de (novos) sentidos. (ROJO; BARBOSA, 2015, p. 123-124).

Nesse cenário, um dos muitos desafios que atravessam o campo da educação na contemporaneidade se refere à integração dessas práticas de (multi)letramentos (ROJO, 2012; ROJO, 2013; STREET, [1995] 2014; THE NEW LONDON GROUP, 1996) nos processos de ensino-aprendizagem. Embora elas estejam presentes nas relações sociais cotidianas de grande parte de docentes e discentes e, mesmo se configurando como uma temática entre as discussões teóricas do campo da educação, inclusive na Linguística Aplicada (LA) (LEMKE, 2010; OLIVEIRA e SZUNDY, 2014; PAIVA, 2013; ROJO, 2012; ROJO, 2013; THE NEW LONDON GROUP, 1996), há ainda diversas lacunas que interferem na (re)constituição de espaços democráticos de (multi)letramentos digitais na educação formal do Brasil, como a falta de equipamentos tecnológicos digitais e de conexão à internet nas escolas públicas.

Desde 1997, foram criadas políticas públicas no país com o propósito de subsidiar as escolas com recursos tecnológicos e capacitação docente para promover espaços de ensino-aprendizagem com o uso das novas tecnologias por meio de alguns programas do Ministério da Educação (MEC). No entanto, os dados da última pesquisa, realizada em 2018 pelo Centro Regional de Estudos para o Desenvolvimento da Sociedade da Informação (Cetic.br), indicam, por exemplo, que, além dos poucos recursos tecnológicos disponíveis nas escolas da região Norte brasileira, os professores de sessenta e cinco por cento das escolas urbanas dessa região não receberam formação para usar o computador e a internet em atividades de ensino-aprendizagem (CETIC, [2018] 2020).

Essa problemática também está presente em documentos que orientam a formação inicial de professores de linguagens, como os projetos curriculares/pedagógicos (PPC/PPP) de formação de professores, mais especificamente dos cursos de Letras das universidades brasileiras. Em relação a tais documentos, Paiva (2013) aponta que os PPC/ PPP não cumpriam o inciso VI do art. $2^{\circ}$ da então vigente Resolução sobre formação docente de 2002 , o qual estabelecia que os currículos deveriam abranger o uso das tecnologias da informação e comunicação, metodologias, estratégias e materiais de inovação. Segundo a autora, o que havia até o momento eram somente projetos isolados de alguns professores formadores.

Após amplo debate político-ideológico no campo da educação para reelaboração dos projetos dos cursos de licenciatura, em conformidade à atual Resolução $\mathrm{n}^{\circ}$ 2, de $1^{\circ}$ de julho de 2015 que define diretrizes nacionais para a formação inicial e continuada de professores (DCN), novos currículos foram implementados pelas instituições de ensino superior até julho de 2019, entre eles, o Projeto Político Curricular (PPC) do curso de Letras Inglês (CLLI) da Universidade Federal do Acre (UFAC), campus Floresta, na cidade de Cruzeiro do Sul, o qual definimos como objeto desta pesquisa.

Considerando as problemáticas expostas e a relevância desse PPC como um gênero discursivo que possibilita refletir/refratar sobre a atuação de professores formadores, bem como na "(trans)formação" (OLIVEIRA e SZUNDY, 2014) de docentes em Língua Inglesa na Amazônia, o objetivo² deste estudo é avaliar, sob a ótica da LA in/transdisciplinar (MOITA LOPES, 2006; ROJO, 2006), em que medida o PPC do curso de Letras Inglês da UFAC, campus Floresta, possibilita (ou não) aos discentes o desenvolvimento da curadoria de sentidos em (multi)letramentos digitais, de maneira crítica, ética e estética para a prática docente durante o processo de formação inicial.

Para isso, nos dois primeiros tópicos do artigo apresentamos os pressupostos teórico-metodológicos que fundamentam nossa análise e que têm como fio condutor a Linguística Aplicada in/transdisciplinar (MOITA LOPES, 2006; ROJO, 2006) em articulação com a perspectiva de linguagem do Círculo de Bakhtin (BAKHTIN, [1952-53] 2016; VOLÓCHINOV, [1929] 2017), os estudos sobre (multi)letramentos (STREET, [1995] 2014; THE NEW LONDON GROUP, 1996) e a semiótica (LEMKE, 2010; SANTAELLA, 2004), sendo que, no primeiro tópico, expomos as dinamizações das práticas discursivas e, no segundo, relacionamos essas mudanças com os pressupostos da pedagogia dos multiletramentos. Em seguida, analisamos o corpus de pesquisa que contempla sete excertos

2. O presente estudo utiliza parte do corpus de pesquisa gerado para o desenvolvimento da dissertação de mestrado de Kieling-Santos (2019), orientada por Paula Tatiana Silva-Antunes. 
selecionados do Projeto Político Pedagógico do Curso de Letras Inglês da Universidade Federal do Acre, campus Floresta. Por último, expomos nossas conclusões em relação ao estudo.

\section{DINAMIZAÇÕES DAS PRÁTICAS DISCURSIVAS NA "MODERNIDADE TARDIA"}

A vida humana é (trans)formada pelos sentidos atribuídos aos sorrisos, choros, palavras, entoações, cores, composições, formas, aromas, sabores, olhares, gestos, texturas.... Esses sentidos são experienciados e delineados em cada interação entre o eu e o(s) outro(s) nas práticas discursivas conforme as valorações, as ideologias presentes nas "condições concretas de enunciação" (BAKHTIN, [1952-53] 2016; VOLÓCHINOV, [1929] 2017).

Sob essa perspectiva dialógica da linguagem, a temática, o campo de circulação, o tempo-lugar histórico, o sujeito que enuncia, o auditório social e as relações sociais entre esses sujeitos são elementos que interferem nas escolhas dos signos que compõem um determinado discurso, assim como nas atribuições de significados a ele atribuídos. Essas escolhas semióticas e significações foram definidas por Volóchinov ([1929] 2017) como "acentuação valorativa" (relacionada às questões éticas, políticas, afetivas e estéticas dos participantes do discurso) (ROJO, 2013). Somos, então, curadores de sentidos (ROJO, 2012; ROJO e BARBOSA, 2015) de enunciados concretos, à medida que, dialogicamente, nossa consciência é (trans)formada pela linguagem ao mesmo tempo em que a (trans)formamos ao refletirmos e refratarmos os "signos ideológicos" (VOLÓCHINOV, [1929] 2017).

Para que as práticas discursivas sejam de algum modo inteligíveis nas interações culturais entre o eu e o(s) outro(s), os seres humanos as organizam em "tipos relativamente estáveis de enunciados" — os gêneros discursivos —, os quais são (re) elaborados conforme os conteúdos temáticos que envolvem um determinado campo de circulação discursiva (BAKHTIN, [1952-53] 2016). Por exemplo, no campo da vida pessoal, fazemos uma ligação para um familiar e contamos uma piada a um amigo; no campo artístico-literário, são elaborados poemas, peças teatrais e pinturas; no campo jornalístico-midiático, os profissionais enunciam o ocorrido por meio de reportagens. Além disso, os gêneros discursivos também são dinamizados conforme os "suportes" em que circulam (MARCUSCHI, 2008), tais como folha de papel, outdoor, camiseta, livro, entre outros, pois estes podem modificar a maneira como os textos transitam nas práticas sociais, o modo como os sujeitos organizam os signos para elaborá-los, bem como a recepção e a responsividade dos interlocutores.

Nos tempos-lugares históricos da contemporaneidade da "modernidade tardia" (HALL, 1997), os diversos dispositivos tecnológicos digitais (notebooks, smartphones, tablets...), junto à internet, que conecta conteúdos de diferentes correntes ideológicas de enunciação e campos da atividade humana entre esses dispositivos ao redor do globo terrestre, expandiram os suportes em que se veiculam os gêneros discursivos.

Sobre isso, Araújo (2016) explica que há uma transmutação dos campos da atividade humana para a internet, de modo que jornalistas, artistas, professores, agricultores, profissionais da saúde, políticos, familiares, entre outros agentes sociais possam dinamizar os gêneros discursivos, tornando mais explícito seu caráter dialógico e flexível. Isso ocorre devido aos quatro traços que caracterizam a linguagem hipermídia (SANTAELLA, 2004). Para Rojo (2013, p. 29), essas dinamizações dos gêneros discursivos de diferentes campos são (re)elaboradas a partir das escolhas ideológicas dos recursos semióticos das mídias pelos sujeitos com o propósito de "atingir suas finalidades e ecoar seus temas". A partir dessa ótica, a pesquisadora revisita a teoria dos gêneros discursivos do Círculo de Bakhtin e a representa na figura a seguir. 


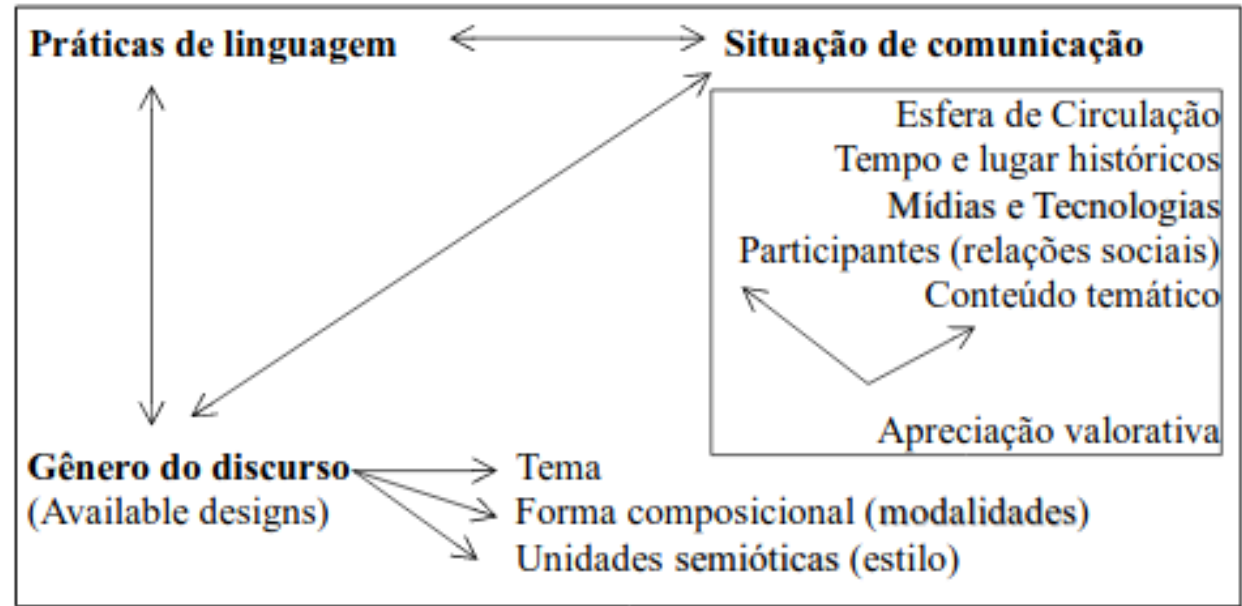

Figura 1. Elementos da teoria bakhtiniana dos gêneros discursivos revisitados

Fonte: Rojo (2013, p. 30).

$\mathrm{Na}$ ampliação de Rojo (2013) à teoria bakhtiniana dos gêneros discursivos, representada na figura 1, a autora acrescenta aos elementos das condições concretas de enunciação (situação de comunicação) as mídias e as tecnologias como parte dos aspectos que refletem na acentuação (apreciação) valorativa dos interlocutores de um determinado discurso. Assim, ao delinear seus enunciados a partir de um gênero discursivo, o usuário das linguagens na contemporaneidade, muitas vezes, recorre a diferentes e diversas modalidades de linguagem (som, gráfico, escrito) (re)inventando a forma composicional de um gênero, ou seja, a maneira como o discurso é organizado e apresentado. Essa composição se baseia no estilo pertinente do campo discursivo e no estilo pessoal do autor, o qual mobiliza unidades semióticas como, por exemplo, o léxico, o tom de voz, a sintaxe, a ordem dos enunciados, a(s) core(s), o tipo de letra, de sons, imagens etc., para enunciar o tema conforme suas ideologias.

Dessa maneira, comentar, postar, taguear, curtir, remixar, editar, filmar, seguir, ser seguido, fotografar, tuitar, assistir ou produzir uma live, ler, selecionar e escrever hipertextos são algumas das práticas de (multi)letramentos sociais (STREET, [1995] 2014; THE NEW LONDON GROUP, 1996), organizadas por gêneros discursivos multissemióticos (ROJO, 2013), que atravessam os diversos campos da atividade humana (BAKHTIN, [195253] 2016) na contemporaneidade. Essas e outras práticas de (multi)letramentos sociais, a nosso ver, deveriam ser contempladas pelos PPC/PPP dos cursos de Letras, pois, nos atuais tempo-espaços históricos, surgem novas formas de se relacionar com os enunciados, distintas dos textos impressos, tanto pelas possibilidades de combinações semióticas quanto pela forma de manusear, criticar, editar, distribuir, colecionar e intervir nos textos (CHARTIER, [1997] 1999). Esse é um fator a ser considerado no contexto de formação de formadores, inclusive de professores de língua inglesa, por provocar mudanças e desafios aos processos de ensino-aprendizagem.

\section{PRÁTICAS DE (MULTI)LETRAMENTOS NA CONTEMPORANEIDADE E SUAS COMPLEXIDADES}

Diante das mudanças das práticas de letramentos e seus desafios nos contextos escolares, o The New London Group, já em 1996, propôs uma abordagem teórica denominada multiletramentos. O prefixo multi- designa tanto as multiplicidades de linguagens que compõem os textos contemporâneos e seus canais de comunicação, quanto a diversidade linguística e cultural que os atravessam a partir dos processos de globalização, cada vez mais intensificados pelas TDIC (ROJO, 2012; THE NEW LONDON GROUP, 1996).

O conceito multiletramentos expressa a necessária reflexão em torno de possibilitar espaços de letramentos escolares que permitam a negociação e a curadoria de sentidos culturais e linguísticos (ROJO, 2012; ROJO e BARBOSA, 2015; ROJO, 2013; THE NEW LONDON GROUP, 1996) em sociedades globais cada vez mais interconectadas, com avanços tecnológicos e, ao mesmo tempo, excludente (OLIVEIRA e SZUNDY, 2014) e violenta. Nesse sentido, a pedagogia de letramentos/alfabetização tradicional que prioriza o ensino da leitura e da escrita sob a perspectiva monolíngue, monocultural, monossemiótica/monomodal e voltada essencialmente aos aspectos de certo modelo de língua, muitas vezes desconectado dos sistemas de regras linguísticas utilizados nas práticas sociais contemporâneas, 
possivelmente, não propiciará o desenvolvimento de condições para que os estudantes de múltiplas e dinâmicas identidades possam participar de maneira democrática dos discursos que circulam na sociedade (THE NEW LONDON GROUP, 1996).

Desse modo, conceitos que definem o propósito da educação - desenvolvimento pessoal, cidadania e qualificação para o trabalho -, os quais estão, inclusive, estabelecidos no artigo $2^{\circ}$ da Lei de Diretrizes e Bases da Educação (BRASIL, 1996), precisam ser deslocados da corrente ideológica nacionalista, monolíngue, monocultural e monomodal/monossemiótica em que a instituição escolar foi gerada pelos Estados-Nações na modernidade. Segundo Rojo (2013 p. 16), "[...] [essas] são as raízes das práticas escolares de letramento sedimentadas que vemos em nossas escolas e nos materiais didáticos [...] que ignoram e ocultam formas sociais [do uso da linguagem] [e deixam] as abordagens discursivas e a réplica ativa em segundo plano".

No quadro a seguir apresentamos os sentidos atribuídos aos signos desenvolvimento pessoal, cidadania e qualificação para o trabalho, pois esses permeiam as relações dialógicas do campo educacional, inclusive, o corpus desta pesquisa. À esquerda do quadro, estão os significados dos fios ideológicos do nacionalismo, do monolinguismo e da monocultura, que constituem o discurso moderno dos Estados-nações. À direita, estão os possíveis deslocamentos ideológicos em contextos contemporâneos da "modernidade tardia" (HALL, 1997). Cabe salientar que os significantes desses signos ideológicos ao mesmo tempo que sofreram certos deslocamentos conforme as dinâmicas sociais, ainda coexistem com perspectivas ideológicas conservadoras. Além disso, essas mudanças não apresentam uma superação do projeto da modernidade (HALL, 1997; ROJO e BARBOSA, 2015).

\section{Quadro 1. As ideologias que atravessam os objetivos da educação}

\begin{tabular}{|l:l|l|}
\hline Modernidade & Modernidade Tardia \\
\hdashline Desenvolvimento Pessoal: Padrões identitários estáveis & Desenvolvimento Pessoal: Pluralidade identitária a partir das infinitas \\
pautados em identidades coletivas, por exemplo, na & possibilidades de identificações pessoais; diversidade; padrões de \\
comunidade nacional, na raça e no gênero; fronteiras & "estilo de vida soft" (HALL, 1997, p. 8), individualismo; publicidade \\
socialmente delineadas entre a vida privada e a vida & da vida pessoal; empoderamento e autonomia para denunciar \\
pública. & preconceito e qualquer outro tipo de violência. \\
\hdashline Cidadania: Relevância dos espaços públicos; Cultura & Cidadania: Geopolítica neoliberal em conflito com o papel \\
nacionalista, patriota, homogênea, monocultural; & e responsabilidade das instituições públicas em detrimento \\
domínio estatal sobre a cidadania; Padronização/ & do mercado; "o governo pela cultura" (HALL, 1997, p. 23); \\
assimilação das línguas nacionais e o apagamento das & Letramentos críticos, pluralismo cultural e linguístico. \\
línguas minoritárias, como as indígenas. & \\
\hdashline Qualificação profissional: Capacidade para empregar & Qualificação profissional: Capacidade para desenvolver projetos \\
e repetir técnicas para a produção de produtos em & complexos e utilizar e desenvolver softwares, aplicativos digitais e \\
massa; relacionar-se por meio do comando e controle & interfaces gráficas; relacionar-se de maneira flexível em equipes \\
hierárquico de cargos profissionais e por meio de & por meio de treinamentos e orientações para superar os desafios; \\
linguagens escritas e formais delineadas a partir de & identificar-se e motivar-se com os valores institucionais; comunicar- \\
gêneros discursivos como o ofício e o memorando. & se por meio de linguagens orais mais informais, plataformas e \\
& aplicativos digitais institucionais e, redes sociais como o e-mail, o \\
& whatsapp, instagram, entre outros; desenvolver redes de contatos \\
\hline
\end{tabular}

Fonte: Elaborado pelas autoras com base em The New London Group (1996) e Hall (1997).

Podemos perceber no quadro 1 que os sentidos atribuídos aos âmbitos da vida privada, vida pública e da vida profissional, foram, na "modernidade tardia" (HALL, 1997), de certa maneira, (re) significados, bem como as relações do poder estatal e/ou do empregador. Alguns desses possíveis deslocamentos ideológicos se deram pelas possibilidades de trocas e escolhas, intensidade dos fluxos migratórios, maior protagonismo social, desenvolvimento tecnológico e de algumas obtenções de direitos sociais.

No entanto, as modificações em torno das formas de produção e de consumo, a conquista por "estilos de vida soft" (HALL, 1997, p. 8) e o prazer são, em grande parte, o cerne das ideologias que delineiam as práticas contemporâneas (ROJO e BARBOSA, 2015). Apesar das relações de trabalho serem configuradas com certa horizontalidade com base no discurso colaborativo do treinamento e da orientação, elas também podem configurar novas formas de 
controle à lógica do mercado (THE NEW LONDON GROUP, 1996). Além disso, a vida cotidiana é atravessada por mensagens sedutoras das "tendências e modas mundiais" que orientam a mecanização e a mercantilização da (trans) formação da identidade (HALL, 1997, p. 22). Nesse contexto,

somos impelidos a buscar a novidade o tempo todo, a não prescindir dela. A superficialidade se estabelece como corolário: curtir/ comentar nas redes sociais, sem refletir sobre o que se lê, apenas para não perder a oportunidade de se posicionar, na verdade, de aparecer ou de se satisfazer (o reino da opinião pessoal no lugar de uma posição ou projeto político mais consistente). (ROJO e BARBOSA, 2015).$^{3}$

Também podemos elencar outras questões relacionadas às práticas discursivas em ambientes digitais em contextos contemporâneos que podem impactar negativamente em nossas vidas. Por exemplo, temos os dados recolhidos por cookies que, além de armazenarem nossas informações pessoais para fins mercadológicos e para certos controles estatais, os quais Hall $(1997$, p. 23) define como "governo pela cultura", acabam direcionando nossas pesquisas de busca, enviando mensagens e sugestões de vídeos, reportagens, propaganda e, fake news o que, de certa maneira, limita nossas alternativas de escolhas. Outro impacto negativo pode ser a exposição da vida privada por muitos adolescentes nas redes sociais, que poderá lhes trazer problemas futuros (TAPSCOTT, 2010), como atrair pessoas mal-intencionadas, capazes de lhes causar danos materiais, psíquicos e físicos. Há também a diminuição do contato com os elementos da natureza e com o(s) outro(s) de maneira presencial em detrimento de "ciberidentidades" (HALL, 1997, p. 23) e a menor apreciação por atividades que têm maior envolvimento de outros órgãos dos sentidos como dançar, pintar, desenhar. Por fim, podemos listar uma maior visibilidade de comunidades com fins de perpetuação de ódio, de preconceito, de violência sexual, entre outros crimes comuns em meios digitais, além da prática do cancelamento, que promove, com base em interesses, o linchamento público de celebridades e influenciadores digitais.

Por outro lado, a hipermídia permite a combinação do hipertexto com multimídias e multilinguagens (SANTAELLA, 2004), o que oportuniza espaços de letramentos de semioses combinatórias, diferentemente da perspectiva "logocêntrica" e grafocêntrica, que tem sido, para Lemke, orientadora de teorias de ensino-aprendizagem. Para ele,

enquanto as crianças estão aprendendo a distinguir recursos semióticos diferentes (por exemplo, desenhando e escrevendo) e portanto dando vazão a espaços combinatórios mais amplos para usá-los de formas coordenadas, nós estamos apenas ensinando-as a usar uma delas: a escrita. (LEMKE, 2010, p. 462).

Além disso, a partir das conexões dos nós de informação, os sujeitos no ciberespaço podem delinear "múltiplos e divergentes" caminhos de leituras, de acessos às informações e de pesquisas sem limites "rígidos" e lineares como o do texto da linguagem verbal impressa (SANTAELLA, 2004) ou de um acervo de uma determinada biblioteca. Esses textos ainda podem ser (re)elaborados/remixados conforme as possibilidades de interação, como no caso dos hipertextos colaborativos, como, a enciclopédia Wikipédia e os fanfics. Também não podemos deixar de mencionar as diversas e plurais "relações dialógicas" (BAKHTIN, [1952-53] 2016) possíveis no ciberespaço. Pessoas de diferentes lugares da Terra podem conhecer, interagir a partir de múltiplas línguas e culturas e abrir espaços multi/ inter/transculturais de enunciação para reivindicar justiça, democracia e direitos sociais. Podemos mencionar como exemplo as manifestações de 2020 do movimento "Black Lives Matter" devido ao assassinato de George Floyd. As manifestações ganharam força ao redor do planeta a partir das redes sociais e foi o estopim para outras reivindicações relacionadas às diversas "asfixias" das sociedades contemporâneas ("EU NÃO CONSIGO RESPIRAR!", 2020). Essas possíveis relações dialógicas permitem o desenvolvimento do "pluralismo cívico", em lugar da concepção de cidadania nacionalista monocultural e mono linguística (THE NEW LONDON GROUP, 1996).

Em decorrência dessa complexidade que envolve as práticas de (multi)letramentos na contemporaneidade, o The New London Group propôs um design da pedagogia dos multiletramentos. Na figura a seguir, expomos os quatro "movimentos pedagógicos" (ROJO, 2012) que constituem esse design, os quais relacionam-se entre si de maneira complexa e não linear (THE NEW LONDON GROUP, 1996).

3. Esses são elementos que podemos observar nos discursos da atual gestão do Governo Federal e de seus seguidores, por meio de textos que postam nas redes sociais, pois, além de cultivarem preconceitos essencialistas de identidade, cultura e crenças, bem como o ataque à democracia, não fornecem projetos políticos às demandas sociais. 


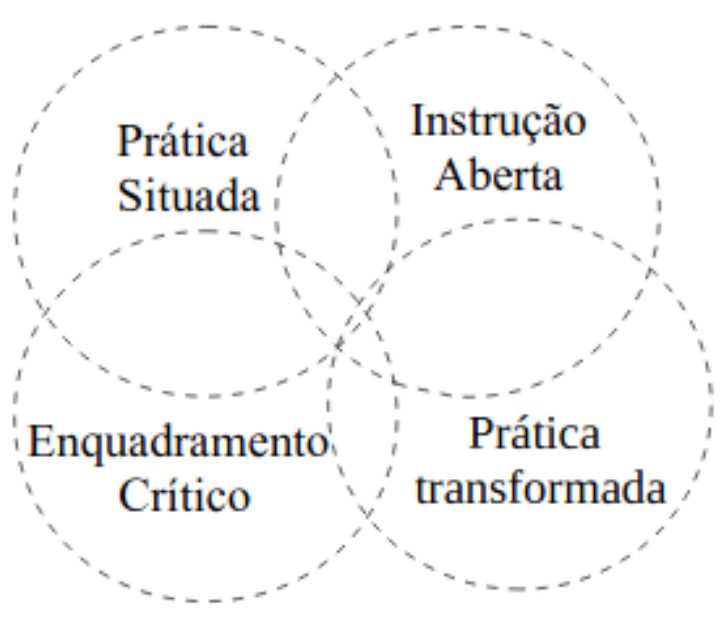

Figura 2. Pedagogia dos Multiletramentos

Fonte: Elaborada pelas autoras com base em The New London Group (1996) e Rojo (2012).

O movimento Prática Situada refere-se à constituição de espaços de letramentos baseados em enunciados e práticas sociais concretas que tenham significados afetivos com a vida dos estudantes de modo que possam protagonizar situações de letramentos conforme suas vivências. Esses espaços devem ser suficientemente motivadores a ponto de possibilitar que "[...] todos os estudantes se sintam seguros em assumir riscos e confiar na orientação de outras pessoas - colegas e professores4." (THE NEW LONDON GROUP, 1996, p. 22, tradução nossa).

Em Instrução Aberta os autores explicam que professores devem ajudar os alunos a delinear os caminhos de aprendizagem e a conscientizar-se sobre esses processos ao contrário da relação de professores como transmissores de conhecimentos e os estudantes como receptores (THE NEW LONDON GROUP, 1996).

O enquadramento crítico objetiva o delineamento de práticas de letramentos que favoreçam o desenvolvimento da criticidade sobre a materialidade discursiva e suas respectivas valorações, tais como os aspectos históricos, sociais, culturais e político-ideológicos presentes nos enunciados (THE NEW LONDON GROUP, 1996).

A Prática transformada refere-se ao desenvolvimento da capacidade reflexiva dos estudantes para produzir e praticar os conhecimentos conforme suas valorações e objetivos em contextos sociais diversos (THE NEW LONDON GROUP, 1996).

Nessas condições concretas de enunciação, expostas nos tópicos 1 e 2 deste artigo, "de mundos crescentemente múltiplos e - o que é mais desconcertante - virtuais", marcados pelos impactos das transformações dos sistemas semióticos, as lutas pelo poder tornam-se cada vez mais simbólicas/discursivas (HALL, 1997, p. 20), acarretando a necessidade de se refletir/refratar sobre uma educação de professores "[...] múltipla, inter/transdisciplinar, situandose entre fronteiras, demandando práticas pedagógicas realizadas em salas de aula uma noção de linguagem também múltipla, complexa [...]" (OLIVEIRA e SZUNDY, 2014, p. 185).

Com base nessa proposição, é relevante que os professores de língua inglesa, do contexto em estudo, desenvolvam também a capacidade para "curar" sentidos (ROJO, 2012; ROJO e BARBOSA, 2015) no "ciberespaço" (SANTAELLA, 2004) de maneira crítica, ética e estética a partir das necessidades dos contextos e saberes locais da Amazônia (UCHÔA, 2014) e, através de discursos na/da língua inglesa como Global English (RAJAGOPALAN, 2009) ou, ainda, de práticas translíngues (CANAGARAJAH, 2013), a fim de possibilitarem em suas práticas docentes espaços plurais de (multi)letramentos.

Em consonância à Rojo (2013), Oliveira e Szundy (2014) e Rojo e Barbosa (2015), sob a ótica in/transdisciplinar da LA, de que a articulação entre a perspectiva dialógica da linguagem do Círculo de Bakhtin e os pressupostos dos multiletramentos (THE NEW LONDON GROUP, 1996) pode apontar possibilidades à (trans)formação de professores e às práticas de letramentos escolares responsivos às conjunturas contemporâneas, analisamos, no tópico seguinte, em que medida o PPC em foco apresenta (ou não) condições para os discentes de Letras-Inglês desenvolverem a curadoria de sentidos às demandas sociais das práticas de linguagens aqui apresentadas.

4. "[...] all learners are secure in taking risks and trusting the guidance of others - peers and teacher." (THE NEW LONDON GROUP, 1996, p. 22). 


\section{AS POSSIBILIDADES PARA O DESENVOLVIMENTO DA CURADORIA DE SENTIDOS EM (MULTI)LETRAMENTOS DIGITAIS PROPOSTAS NO PPC}

Neste tópico, analisamos excertos selecionados do Projeto Político Curricular (PPC), do Curso de Licenciatura em Letras-Inglês (CLLI) da Universidade Federal do Acre (UFAC) - campus Floresta, em vigência desde o primeiro semestre de 2019. Durante a geração de dados da pesquisa de mestrado (KIELING-SANTOS, 2019), identificamos, por meio de pesquisa documental indireta (MARCONI e LAKATOS, 2001), dezesseis enunciados que tratam da temática TDIC, os quais foram separados em duas categorias analíticas devido às suas especificidades. Na primeira, analisamos cinco excertos referentes ao "papel do CLLI em relação às TDIC na formação de professores". Na segunda categoria, analisamos onze excertos considerados "as aprendizagens de (multi)letramentos para o uso das TDIC" proporcionadas durante o curso de graduação. Para atingir o objetivo proposto neste artigo, bem como contemplar o estilo sintético desse gênero discursivo, selecionamos sete enunciados da segunda categoria por esses subsidiarem de maneira mais específica a possibilidade para o desenvolvimento da "curadoria de sentidos" em multiletramentos digitais aos discentes, sendo dois excertos referentes ao perfil do egresso do CLLI, e cinco excertos referentes às ementas das disciplinas ${ }^{5}$.

Ao considerarmos os enunciados que compõem o perfil do egresso como delineadores das capacidades que devem ser desenvolvidas em relação ao uso das TDIC pelos discentes do curso, e as ementas dos componentes curriculares como as sínteses dos conteúdos temáticos que devem ser ministrados pelos professores do curso a fim de possibilitar a "(trans)formação" docente (OLIVEIRA e SZUNDY, 2014), analisamos os excertos do perfil do egresso em articulação com as ementas das disciplinas. Isso porque esse critério de análise permite que se coloque em paralelo o que se espera do perfil dos professores formados no CLLI a partir dos conteúdos e ferramentas que lhes foram ofertadas durante sua formação inicial. Além desses excertos mencionados, consideramos também para a análise a organização curricular do PPC.

Segundo os pressupostos do documento, a organização curricular do CLLI está orientada de acordo com os três núcleos definidos pela Resolução n ${ }^{\circ}$ 2, de $1^{\circ}$ de julho de 2015 do CNE (MEC, 2015), os quais são: núcleo de formação geral; núcleo de aprofundamento e diversificação das áreas de atuação profissional e núcleo de estudos integradores. Esses núcleos estão aglutinados em três eixos - formação geral, formação específica (que contempla estudos linguísticos e literários e formação profissional) e formação integrada - em conformidade com a Resolução CNE/CES 18, de 13 de março de 2002, que reconhece as Diretrizes Curriculares para os Cursos de Letras (UFAC, 2018). Cada um dos eixos mencionados apresenta diversos conteúdos, entre eles as TDIC, os quais estão contemplados nos componentes curriculares do CLLI de maneira articulada (UFAC, 2018).

No primeiro excerto analisado, "[...] o uso de novas tecnologias [...]" (UFAC, 2018, p. 27) como requisito do perfil do egresso do CLLI está associado às condições concretas de enunciação dos contextos amazônicos, ao objeto de estudo do professor de língua inglesa, assim como ao caráter reflexivo que envolve a (trans)formação docente (OLIVEIRA e SZUNDY, 2014).

\begin{tabular}{|l|l|}
\hline Excerto 1 & {$[\ldots$.$] o egresso do CLLI, no contexto local, deverá ser capaz de refletir teoricamente sobre a$} \\
Perfil do & linguagem, fazendo uso de novas tecnologias e compreendendo a sua formação profissional como \\
egresso do & processo contínuo, autônomo e permanente numa realidade que o convoca a refletir a própria \\
CLLI & qualidade de vida na Amazônia (UFAC, 2018, p. 27).
\end{tabular}

Nesse excerto, "[a capacidade] de refletir teoricamente sobre a linguagem" é uma das aprendizagens que deve delinear o perfil do egresso do CLLI. Essa aprendizagem, objeto de estudo do professor de linguagens, é especificada conforme seus aspectos enunciativos, os quais são: usar novas tecnologias; compreender a responsabilidade e o caráter contínuo da formação docente e refletir sobre a vida nos contextos amazônicos. Tais aspectos vão ao encontro dos pressupostos de (CELANI, [2001] 2008) sobre a necessidade de a formação de professores de línguas estrangeiras exceder os aspectos técnicos profissionalizantes, de modo a propiciar o desenvolvimento do perfil docente reflexivo sobre seu objeto de estudo - as linguagens na/da vida.

5. Além dessas cinco ementas transcritas para a análise, foram mencionadas, neste tópico e na conclusão, outras ementas do PPC (em foco), as quais podem ser consultadas no ementário da UFAC por meio do link: $<$ https://portal.ufac.br/ementario/curriculo.action?v=394>. 
Nesse sentido, a capacidade para o uso das novas tecnologias traçada no perfil do egresso, no excerto 1, está em consonância à possibilidade do desenvolvimento da curadoria de sentidos de maneira crítica e ética em (multi) letramentos digitais, pois, em espaço-tempos da modernidade tardia em que as relações de poder são, cada vez mais, simbólicas/discursivas (HALL, 1997) e imersas no ciberespaço (SANTAELLA, 2004), é essencial que o professor de língua inglesa seja consciente de que suas escolhas teóricas são também escolhas ideológicas e implicam a vida do outro (OLIVEIRA e SZUNDY, 2014) (nesse caso, seus discentes). Assim, é necessário que o professor desenvolva a responsividade para refletir/refratar sobre as epistemologias linguísticas que permeiam as políticas de ensino, os textos, os materiais didáticos, as formas de avaliação, a ministração de aulas, dentre outros discursos que integram a prática docente.

Além disso, o excerto em análise pontua a necessidade de o egresso ser capaz de refletir sobre a qualidade de vida no seu contexto de atuação, a Amazônia, o que condiz com os propósitos da educação definidos na LDB (BRASIL, 1996) - desenvolvimento pessoal, cidadania e qualificação para o trabalho - e, também, discutidos pelo The New London Group (1996). Pensar sobre a "qualidade de vida na Amazônia", em especial, no Vale Juruá, durante a formação inicial e, a posteriori, como egresso, implica refletir sobre contextos amazônicos cultural, linguística e biologicamente múltiplos, diversos e conectados, interdependentes com o global. Ao mesmo tempo, são contextos marcados pelos impactos nas formas de vida e nas linguagens dos povos indígenas, principalmente, durante o violento processo de ocupação do Estado brasileiro no primeiro ciclo da borracha (MARTINI, 2019) que ainda, na atualidade, refletem políticas linguísticas e discursos excludentes. Também são marcados pelos fluxos migratórios e por constantes ataques ao meio ambiente. Tais questões implicam os âmbitos da vida pessoal, social e da qualificação para o trabalho e devem ser consideradas no planejamento docente.

Com base na análise do excerto 1, passamos agora a analisar se as ementas das disciplinas, excertos 2 e 3, apresentam conteúdos que permitem aos discentes do CLLI desenvolver a curadoria de sentidos em ambientes digitais de maneira reflexiva e em consonância aos contextos amazônicos.

A ementa da disciplina Língua Inglesa II, excerto 2, é semelhante às demais disciplinas de Língua Inglesa, ofertadas desde o $1^{\circ}$ ao $8^{\circ}$ período do curso. Todas apresentam situações discursivas para aprendizagem da língua inglesa, ou seja, práticas sociais que privilegiem o uso dessa língua, incluindo aquelas mediadas pelas tecnologias, bem como os campos da atividade humana. A diferença entre elas são os focos de modalidades de uso da língua (leitura, escrita, escuta, oralidade), os conteúdos referentes aos aspectos linguístico-discursivos e a ênfase no desenvolvimento de competências de uso da língua inglesa.

\begin{tabular}{|c|c|}
\hline $\begin{array}{l}\text { Excerto } 2 \\
\text { Ementa da } \\
\text { disciplina } \\
\text { Língua } \\
\text { Inglesa II }\end{array}$ & $\begin{array}{l}\text { Representação social da língua inglesa nas diversas manifestações das práticas de linguagem do } \\
\text { cotidiano, interculturais, político-cidadãs, investigativas, práticas mediadas pelas tecnologias da } \\
\text { informação e comunicação, práticas do trabalho. Compreensão e produção escrita e oral. Aspectos } \\
\text { fonológicos, morfossintáticos e discursivos da língua inglesa de maneira integrada. Ênfase no } \\
\text { desenvolvimento da produção e compreensão oral. (UFAC, 2018, p. 50). }\end{array}$ \\
\hline
\end{tabular}

Identificamos, então, que todas as ementas das disciplinas de Língua Inglesa do curso estão delineadas pela "representação social da língua inglesa nas diversas manifestações da linguagem [...]" (UFAC, 2018, p. 50) e podem propiciar situações autênticas do uso da LI para a aprendizagem dos aspectos linguísticos e discursivos dessa língua. Nesse sentido, as ementas das disciplinas abrem possibilidades para que os professores ministrantes tenham a oportunidade de promover, a depender de suas escolhas didático-pedagógicas, de suas formações, de acessibilidade a equipamentos, entre outros fatores, espaços de (multi)letramentos (STREET, [1995] 2014; THE NEW LONDON GROUP, 1996) em ambientes digitais a partir da prática situada (THE NEW LONDON GROUP, 1996) por meio de gêneros discursivos multissemióticos (ROJO, 2013) com temáticas locais da Amazônia (UCHÔA, 2014) e globais, tais como postagens nas redes sociais que tratem de temas cotidianos; memes, charges digitais, podcasts e programas eleitorais, relacionados aos temas políticos, ambientais e outros que interferem na sociedade; vídeo-minuto, playlist comentadas e outros do campo artístico-literário; manifestos, periódicos acadêmicos online; videoaulas de canais e temáticas pertinentes aos conteúdos ministrados na disciplina e ao conhecimento linguístico-discursivo do discente/ egresso do CLLI para que desenvolva a capacidade de investigar conteúdos relacionados à sua atuação; e-mail, vídeo de entrevista de apresentação profissional e outros gêneros referentes às práticas de trabalho contemporâneas que demandam o uso das TDIC. 
Além disso, a partir da instrução aberta (THE NEW LONDON GROUP, 1996), docentes formadores podem subsidiar essas práticas de (multi)letramentos no que se refere aos aspectos discursivos e suas ideologias, bem como do sistema linguístico. Assim, poderão ser delineadas tarefas e discussões, através de "processos/ações [como]: seguir/ser seguido; curtir, comentar, compartilhar, redistribuir, remixar; clipar; curar" (ROJO e BARBOSA, p. 142), de modo que sejam considerados o tempo-lugar histórico, os interlocutores, o auditório social, as escolhas estilísticas que envolvem o sistema linguístico como pronúncia e suas variações, ortografia e suas variações em ambientes digitais, sintaxe e outros elementos de acordo com os campos de atividade, a fim de promover espaços para aprendizagem do uso da língua e suas estruturas com enfoque no enquadramento crítico (THE NEW LONDON GROUP, 1996).

As ementas dessas disciplinas também propõem práticas discursivas "interculturais", as quais podem ser contempladas a partir dos gêneros discursivos multissemióticos que circulam no ciberespaço, em Global English (RAJAGOPALAN, 2009) e em práticas translíngues (CANAGARAJAH, 2013). Sob a ótica do Global English, a LI é uma língua dinâmica com diferentes e instáveis variações sociolinguísticas em que não é priorizada a idealização do padrão norte-americano e/ou britânico, permitindo o (re)conhecimento de outros usos da LI como primeira ou segunda língua, por exemplo, pelos falantes indianos, canadenses, jamaicanos, sul-africanos (...) e também de seus usos como língua adicional. Já nas práticas translíngues que envolvem o uso da LI, os interlocutores recorrem aos diferentes códigos linguísticos e semióticos conforme seus contextos de enunciação para expressarem suas identidades múltiplas constituídas em práticas de (multi)letramentos bilíngues/multilíngues e multissemióticas, de modo que possam negociar os significados em espaços (trans)nacionais/culturais. (CANAGARAJAH, 2013).

Ambas as orientações de uso da LI - Global English e práticas translíngues - a partir de gêneros discursivos multissemióticos, têm o potencial de fomentar espaços de (multi)letramentos distintos das práticas escolares enraizadas nos vieses mononoculturais, monolinguístico e monosemióticos (ROJO, 2013).

Nesse sentido, podemos considerar que a ementa pode contribuir para que os professores de língua inglesa em formação inicial,

[...] se tornem analistas dos discursos capazes de engajar os alunos em práticas de análise e (re)construção de significados pautadas nos multiletramentos, ou seja, na articulação entre múltiplas modalidades semióticas e múltiplas culturas. Uma articulação tal pressupõe inter-relações constantes entre as práticas de letramento escolares e àquelas da vida em processos de semiotização de atos éticos. (OLIVEIRA e SZUNDY, 2014, p. 198).

O próximo excerto analisado refere-se à ementa da disciplina Tecnologias da Informação e Comunicação no Ensino, a qual é ofertada no quarto semestre do curso.

\begin{tabular}{|l|}
\hline Excerto 3 \\
Ementa da \\
disciplina \\
Tecnologias da \\
Informação e \\
Comunicação \\
no Ensino
\end{tabular}

A Linguística Aplicada e a aprendizagem mediada por recursos digitais. Estratégias para o desenvolvimento das competências do professor de línguas na era pós-globalizante. Processos de inclusão pelo letramento digital e as tecnologias de informação e comunicação no ensino de língua inglesa. Os gêneros discursivos reelaborados nas ambiências ou plataformas digitais. Técnicas de pesquisa e produção de gêneros acadêmicos nas ambiências digitais. Avaliação e produção de recursos didáticos digitais. (UFAC, 2018, p. 59)

Os enunciados dessa ementa abrangem conteúdos temáticos que proporcionam aos discentes o desenvolvimento da capacidade, delineada no perfil do egresso (excerto 1), de "[...] refletir teoricamente sobre a linguagem" (UFAC, 2018, p. 27) levando em consideração as mudanças das práticas discursivas na contemporaneidade.

A partir desses conteúdos sintetizados na ementa, o docente ministrante da disciplina tem a possibilidade de promover, por exemplo: i) discussões em torno dos conhecimentos produzidos na área in/transdisciplinar da Linguística Aplicada sobre as dinamizações das práticas de linguagens e as possibilidades para a aprendizagem da língua inglesa com o uso das tecnologias digitais; ii) discussões, reflexões e tarefas em relação às mudanças culturais e econômicas no contexto da "era pós-globalizante" (UFAC, 2018, p. 59) que pode remeter à modernidade tardia (HALL, 1997) em que a vida pessoal, social e as opções de trabalho modificaram de maneira complexa e, consequentemente, as maneiras de ensinar e aprender (THE NEW LONDON GROUP, 1996); iii) conhecimentos e pesquisas acerca das políticas de ensino que abrangem a temática da inclusão digital, assim como reflexões e projetos que viabilizem possíveis alternativas para suprir as necessidades do contexto local; iv) o estudo sobre as dinamizações dos gêneros discursivos, o que pode reportar às multiplicidades de linguagens e culturas que compõem os textos 
que circulam no ciberespaço (ROJO, 2006; SANTAELLA, 2004; THE NEW LONDON GROUP, 1996) e suas possíveis estratégias de ensino; v) o estudo, a pesquisa e a produção de gêneros acadêmicos em ambientes digitais, o que é essencial para os discentes participarem ativamente de práticas de pesquisa, de estudo e de elaboração de textos desse campo da atividade humana, assim como das formas de curar, compartilhar e editar esses gêneros configurados na linguagem hipermídia (SANTAELLA, 2004).

Por conseguinte, os conteúdos da ementa da disciplina Tecnologias da Informação e Comunicação buscam promover o desenvolvimento de um profissional da educação responsivo às demandas das práticas didáticas no cenário contemporâneo que diferem de perspectivas unidirecionais, logocêntricas/grafocêntricas de ensino-aprendizagem (LEMKE, 2010). Além disso, a disciplina contempla conteúdos relacionados à temática geral "perspectivas sobre o processo de construção identitárias docente e a concepção do professor como pesquisador diante das tecnologias" do eixo formação geral (UFAC, 2018, p. 33)

Em contrapartida, nas ementas das disciplinas específicas das práticas discursivas acadêmicas, Organização do Trabalbo Acadêmico I e II e Iniciação à extensão, não há conteúdos temáticos referentes à pesquisa e elaboração de gêneros acadêmicos nos ambientes digitais, apesar dessas disciplinas serem muito relevantes para o desenvolvimento do professor-pesquisador.

Uma das razões que podem explicar a ausência de práticas de letramento digital nas disciplinas direcionadas especificamente ao trabalho com o texto acadêmico reside no fato de que a concepção de escrita que permeia o discurso e as práticas da universidade ainda é muito tradicional, como destaca Oliveira-Codinhoto (2019). Assim, por estar baseada essencialmente em concepções de escrita presentes no senso comum, formadas e corroboradas por instituições conservadoras, como a própria universidade (e a escola), a gramática e a imprensa tradicionais, que desempenham funções de prestígio na sociedade, o trabalho com os textos acadêmicos continua atrelado a um papel normatizador e padronizador, a um mero código de conduta que precisa ser aprendido, cultivado e reproduzido. Desse modo, a noção de escrita que emerge desse imaginário circunscreve-se à adequação à norma e aos modelos de gêneros discursivos que circulam na academia, vistos aqui como estáticos e padronizantes. Nessa perspectiva, não há espaço para a produção de textos e de práticas de escrita fora da estaticidade do papel, por assim dizer, ao mesmo tempo que as práticas digitais são encaradas como exteriores à academia, pertencentes ao domínio do lazer, por exemplo.

Portanto, consideramos insuficiente apenas a disciplina Tecnologias da Informação e Comunicação no Ensino contemplar conteúdos que permitem aprendizagens sobre as novas formas de se relacionar com os gêneros acadêmicos para que o discente possa desenvolver capacidades para pesquisar, filtrar, selecionar, criticar, produzir colaborativamente em plataformas digitais, editar, utilizar ferramentas de referenciais bibliográficos e base de dados e outros recursos hipermidiáticos e, assim, participar dos discursos acadêmicos em ambientes digitais que envolvem especificidades do campo.

O excerto 4 refere-se a algumas babilidades delineadas no perfil do egresso do CLLI, como o engajamento no trabalho colaborativo e em equipe, inclusive na elaboração e execução de projetos curriculares e o uso das tecnologias para fins didáticos.

\begin{tabular}{|l|l|}
\hline Excerto 4 & $\begin{array}{l}\text { A elaboração e a execução de projetos de desenvolvimento dos conteúdos curriculares, o uso de } \\
\text { Perfil do egresso }\end{array}$ \\
& $\begin{array}{l}\text { inovadores também devem fazer parte do conhecimento e das habilidades desse egresso que, } \\
\text { ainda deve desenvolver hábitos de colaboração e trabalho em equipe. (UFAC, 2018, p. 28) }\end{array}$ \\
\hline
\end{tabular}

Essas habilidades, delineadas no perfil do egresso do CLLI (excerto 4), estão em consonância com os deslocamentos culturais da "modernidade tardia" (HALL, 1997) no que tange às relações e práticas profissionais. Segundo o The New London Group (1996), no cenário que abrange a década final do século XX, o perfil profissional diferencia-se do modelo fordista hierarquizado por cargos e funções fixas com o propósito da fabricação de produtos em massa, visão que perdura até os dias atuais. Conforme o grupo de intelectuais do New London Group, as relações entre colegas de profissão, em grande parte dos contextos, se estabelecem pela formação de equipes em ambientes colaborativos e de aprendizagem com o propósito do desenvolvimento de projetos criativos e inovadores.

Por esse ângulo, é relevante que docentes em formação inicial possam desenvolver a capacidade para negociar sentidos a fim de atuarem em equipes para solucionar problemas, vislumbrar alternativas, elaborar e executar projetos 
(curriculares e outros), produzir, remixar, compartilhar e avaliar materiais didáticos, bem como promover espaços colaborativos entre seus alunos em práticas de (multi)letramentos.

Do mesmo modo, os contextos de atuação de professores na contemporaneidade demandam, além das práticas discursivas presenciais, a negociação e curadoria de sentidos através de gêneros discursivos virtuais que envolvem a linguagem hipermídia e a conexão em rede para relacionarem-se com os colegas da comunidade escolar e com os alunos, assim como para colocarem em prática projetos e estratégias de ensino-aprendizagem de discursos interculturais em língua inglesa com o uso de aplicativos, plataformas educacionais, redes sociais, recursos multimídias, dentre outros. ${ }^{6}$

Cabe ressaltar que essas práticas discursivas e colaborativas, orientadas com base na ética e na criticidade, privilegiam condições mais democráticas e plurais de (multi)letramentos para que os estudantes desenvolvam a capacidade de negociar e participar criticamente dos discursos do campo profissional, distanciando-se de um perfil tecnocrata que forma estudantes dóceis e adequados à lógica do mercado (THE NEW LONDON GROUP, 1996) na "modernidade tardia" (HALL, 1997).

Identificamos três disciplinas (excertos 5, 6 e 7) que contemplam conteúdos para o desenvolvimento de habilidades apresentadas no perfil do egresso (excerto 4) que definem o uso das TDIC para fins didáticos e possibilitam o trabalho colaborativo em equipe.

\begin{tabular}{|l|l|}
\hline $\begin{array}{l}\text { Excerto } 5 \\
\text { Ementa da } \\
\text { disciplina Ensino }\end{array}$ & $\begin{array}{l}\text { Concepção de linguagem e de ensino. Métodos e abordagens de ensino. A abordagem de } \\
\text { ensino de língua inglesa norteada por gêneros discursivos. A prática pedagógica e os Parâmetros } \\
\text { Curriculares Nacionais para o ensino fundamental - anos finais e a Base Nacional Comum } \\
\text { Curricular, documento introdutório, específico e dos temas transversais, diversidade de gênero, } \\
\text { Lexual, religiosa, de faixa geracional. Conhecimentos práticos sobre os procedimentos de ensino }\end{array}$ \\
& $\begin{array}{l}\text { da língua inglesa no contexto da educação básica: anos finais do ensino fundamental (identificação } \\
\text { e avaliação do livro didático, mídias digitais, livro do professor, diretrizes nacionais e estaduais de } \\
\text { ensino, sequências didáticas, etc.). (UFAC, 2018, p. 65) }\end{array}$ \\
\hline
\end{tabular}

\begin{tabular}{|c|c|}
\hline ansino & $\begin{array}{l}\text { Organização do trabalho pedagógico na área considerando as Diretrizes Curriculares Nacionais } \\
\text { do Ensino Médio, Parâmetros Curriculares Nacionais para o Ensino Médio, os PCNs e as } \\
\text { Orientações Curriculares para o Ensino Médio. A Base Nacional Comum Curricular. Concepções } \\
\text { de didáticas de línguas na era pós método. Avaliação e produção de material didático e sequência } \\
\text { didáticas voltados para o ensino médio. Conhecimentos práticos sobre os procedimentos de } \\
\text { ensino da língua inglesa no contexto da educação básica: ensino médio (identificação e avaliação } \\
\text { do livro didático, mídias digitais e livro do professor, diretrizes nacionais e estaduais de ensino, } \\
\text { sequências didáticas, etc.). (UFAC, 2018, p. 69) }\end{array}$ \\
\hline
\end{tabular}

As ementas das disciplinas Ensino da Lingua Inglesa I e Ensino da Língua Inglesa II têm "as mídias digitais" como um dos conteúdos referentes aos "conhecimentos práticos sobre os procedimentos de ensino da língua inglesa no contexto da educação básica [...]" (UFAC, 2018, p. 65-69), sendo a primeira com foco nos anos finais do ensino fundamental e a segunda com foco no ensino médio (por isso as analisamos concomitantemente). Esse conteúdo, portanto, deve promover a alunos-professores o desenvolvimento da capacidade para (re)elaborar, utilizar e avaliar materiais didáticos conforme as necessidades dos contextos em que atuam/atuarão, bem como de se engajarem em equipes, caso o docente ministrante da disciplina oportunize esses espaços colaborativos entre os discentes.

Ambas as disciplinas também apresentam como conteúdos os documentos das políticas nacionais de ensino básico, o que é muito relevante para que os docentes em formação possam conhecer e articular sobre elas, assim

6. Presenciamos, de forma mais evidente, a necessidade de construir práticas didáticas em meios virtuais durante a pandemia da Covid-19, que eclodiu no início de 2020. Por ser o isolamento social a medida mais eficaz no combate à doença, aulas presenciais foram suspensas em todo o país e muitas instituições escolares promoveram ensino remoto emergencial. Dessa maneira, os professores têm enfrentado grandes desafios para a construção de estratégias de ensino-aprendizagem em contexto virtual. Contudo, cabe ressaltar que, apesar de as práticas de ensino-aprendizagem de maneira remota (por meio da internet, da televisão e do rádio) ajudarem a manter o vínculo dos estudantes com a escola, não deveriam/devem ser substituídas pela carga-horária presencial para que não se comprometa o acesso à educação e sua qualidade, conforme explicam Honorato-Santos, Rossi e Oliveira (no prelo) sobre a execução do Parecer do Conselho Nacional de Educação - CNE $n^{\circ}$ 5/2020 na rede pública de ensino do Estado do Acre. 
como desenvolver e executar os projetos curriculares dos seus contextos de atuação, bem como seus planejamentos de ensino-aprendizagem.

Na disciplina Ensino da Língua Inglesa I os temas transversais são definidos como conteúdos e estão presentes na Resolução ${ }^{\circ}$ 2, de $1^{\circ}$ de julho de 2015 do CNE (MEC-CNE, 2015) que estabelece as diretrizes para formação docente e também nos documentos que orientam a educação básica, com exceção da Base Nacional Comum Curricular (BNCC) (BRASIL, 2018). Após discussões político-ideológicas que refletiram em mudanças na LDB (BRASIL, 1996) pela Lei 13.415 (BRASIL, 2017), os temas transversais foram retirados das versões homologadas da BNCC (BRASIL, 2018) e estabelecidos apenas como conteúdos para projetos e pesquisas a critério dos sistemas de ensino.

Contudo, esses temas são de suma relevância para as práticas de (multi)letramentos em contextos escolares, inclusive aquelas que envolvem os ambientes digitais, pois estas devem estar pautadas numa política pluralista que considere a heterogeneidade de identificações pessoais, como credo, linguagens, gênero e sexualidade (THE NEW LONDON GROUP, 1996), entre outros aspectos culturais que envolvem os temas transversais. Por isso, esses temas condizem com conteúdos curriculares para a formação ética, estética e crítica de professores de língua inglesa.

Na mesma perspectiva, a disciplina eletiva Laboratório e Produção de Material Didático em Língua Inglesa (excerto 7) contempla conteúdos para o desenvolvimento de professores responsivos às práticas de (multi)letramentos contemporâneas.

\begin{tabular}{|l|l|}
\hline Excerto 7 & Fundamentos conceituais acerca de abordagens e processos para análise e produção de material \\
Ementa da & didático no ensino de Língua Inglesa (LI). Os componentes do material didático: unidades e \\
disciplina & tarefas na integração das habilidades linguísticas e comunicativas no ensino de LI. Abordagens \\
Laboratório e & contemporâneas na produção de material didático no ensino de LI. A tecnologia e a produção \\
Produção de & de materiais didáticos. Princípios balizadores na seleção e definição de materiais didáticos \\
Material didático & específicos para diferentes contextos. Questões de autenticidade na produção do material \\
em Língua & didático. (UFAC, 2016, p. 80) \\
Inglesa & \\
\hline
\end{tabular}

Os conteúdos da ementa permitem que alunos-professores a partir da reflexão/refração das necessidades afetivas e socioculturais dos seus futuros alunos, aprendam a produzir e selecionar materiais didáticos, tanto aqueles ofertados pelo Ministério da Educação (MEC) pelo programa do Plano Nacional do Livro Didático e Guia das Tecnologias, como também os que são compartilhados por outros docentes e/ou pesquisadores no ciberespaço e podem ser remixados.

Nesse sentido, a ementa condiz com uma formação de profissionais "responsáveis e responsivos" num contexto local marcado pela diversidade e fluxos, ao mesmo tempo, interconectado ao global que demanda "um trabalho docente com as linguagens no sentido de contribuir com a construção de sujeitos capazes de transitar, compreendendo, interpretando e respondendo, a partir de posicionamentos valorados, (a)os discursos produzidos e circulantes nessa sociedade" (OLIVEIRA e SZUNDY, 2014, p. 186).

Esses conteúdos podem possibilitar, ainda, que os alunos-professores desenvolvam o movimento pedagógico da prática transformada (THE NEW LONDON GROUP, 1996) ao elaborarem, remixarem um material didático com o uso das TDIC conforme a situação de enunciação, o que implica o enquadramento crítico (THE NEW LONDON GROUP, 1996) em relação às escolhas discursivas multissemióticas e à proposição de tarefas aos estudantes. Desse modo, a disciplina poderá abrir alternativas à reprodução de metodologias prescritivas baseadas nos aspectos sistêmicos da língua (UCHÔA, 2014) e dos materiais da indústria de ensino que não consideram os aspectos locais e afetivos dos estudantes (KUMARAVADIVELU, 2006).

Em nossas análises, também constatamos que não há nenhuma menção às TDIC nos enunciados que compõem as ementas das disciplinas de literatura, apesar de um dos conteúdos propostos na organização curricular do PPC ser "literatura em língua portuguesa e em língua inglesa: suas interfaces com demais sistemas culturais, artísticos e midiáticos" (UFAC, 2018, p. 33). Desse modo, acabaram sendo negligenciadas as "novas estéticas" que compõem os "gêneros multissemióticos" (ROJO, 2012, 2013) do campo artístico-literário e fazem parte dos (multi)letramentos contemporâneos, como, machinemas, remixes, animes, fanfics, fanclips. 


\section{CONSIDERAÇÕES FINAIS}

Tendo como fio condutor os pressupostos teórico-metodológicos da LA in/transdisciplinar (MOITA LOPES, 2006; ROJO, 2006) em diálogo com Bakhtin ([1952-53] 2016), Volóchinov ([1929] 2017), Street ([1995] 2014), The New London Group (1996), Lemke (2010), Santaella (2004), entre outros, analisamos, neste artigo, sete excertos do Projeto Político Curricular do Curso de Letras Inglês da Universidade Federal do Acre, campus Floresta, com o propósito de avaliar em que medida esse documento possibilita (ou não) aos discentes o desenvolvimento da curadoria de sentidos em (multi)letramentos digitais de maneira crítica, ética e estética para a prática docente durante o processo de formação inicial.

O estudo apontou que as práticas discursivas com o uso das TDIC são consideradas relevantes e estão presentes na política de formação docente. Conforme a análise de dois excertos que traçam o uso das TDIC como requisito do perfil do egresso do CLLI e de cinco excertos das ementas das disciplinas que definem conteúdos temáticos relacionados às TDIC, avaliamos que o PPC pretende propiciar aos discentes o desenvolvimento da curadoria de sentidos em (multi)letramentos digitais de maneira crítica, ética e estética, tanto para a aprendizagem dos conteúdos do curso quanto para a prática docente.

Desse modo, diferentemente da conjuntura apontada por Paiva (2013) sobre os projetos políticos curriculares/ pedagógicos dos cursos de Letras anteriores à Resolução $n^{\circ}$ 2, de $1^{\circ}$ de julho de 2015 (MEC - CNE, 2015), o PPC (em foco) propõe que o uso das TDIC na educação de professores não ocorra de maneira isolada a partir de projetos, mas que ela seja uma das capacidades a serem desenvolvidas pelos egressos por meio de diversos conteúdos propostos nas ementas de algumas das disciplinas do curso.

Contudo, a análise também apontou que as disciplinas que visam a aprendizagens específicas à pesquisa acadêmica e às literaturas não apresentam conteúdos relacionados às TDIC em suas ementas, o que poderá resultar em lacunas para o desenvolvimento do perfil de professor-pesquisador e leitor literário em contextos da "modernidade tardia" (HALL, 1997), uma vez que permanece, nessas ementas, uma perspectiva mais tradicional da academia, o que acarreta visões também mais tradicionais de letramentos acadêmicos e artístico-literários, fortemente ancoradas na letra escrita e no papel.

Para concluir, é relevante que se investigue, para além das questões levantadas neste artigo, a atuação dos professores formadores na adesão às políticas educacionais propostas no PCC em relação às TDIC, bem como na (re) elaboração de alternativas às lacunas apresentadas. Portanto, longe de encerrar a questão central aqui discutida, entendemos que este trabalho apenas inicia a reflexão/refração sobre o tema.

\section{REFERÊNCIAS}

ARAÚJO, J. (2016). Reelaboração de gêneros em redes sociais. In: Araújo, J.; Leffa, V. (orgs.), Redes sociais e ensino de línguas: o que temos que aprender. São Paulo: Parábola Editorial, p. 49-63.

BAKHTIN, M. (1978). Os gêneros do discurso. Tradução de Paulo Bezerra. São Paulo: Editora 34, 2016.

BRAIT, B.; CAMPOS, M. I. B. (2009). Da Rússia czarista à web. In: Brait, B. (org.), Bakbtin e o círculo. São Paulo: Contexto, p. $15-30$.

BRASIL. (1996). Lei no 9.394, de 20 de dezembro de 1996. Disponível em: http://www.planalto.gov.br/ccivil_03/leis/19394.htm Acesso em: 12 jul. 2020.

BRASIL. (2017). Lei 13.415, de 16 de fevereiro de 2017. Disponível em: https://www2.camara.leg.br/legin/fed/lei/2017/lei-13415-16fevereiro-2017-784336-publicacaooriginal-152003-pl.html Acesso em: 12 jul. 2020.

BRASIL. Ministério da Educação. (2018). Base Nacional Comum Curricular: educação é a base. Brasília: MEC/SEF. Disponível em: http://basenacionalcomum.mec.gov.br/images/BNCC_EI_EF_110518_versaofinal_site.pdf Acesso em: 12 ago. 2020.

CANAGARAJAH, A. S. (2013). Translingual practice: global Englishes and cosmopolitan relations. New York: Routledge. 
CELANI, M. A. A. (2001). Ensino de línguas estrangeiras: ocupação ou profissão? In: Leffa, V. (org.), O professor de línguas estrangeiras: construindo a profissão. 2. ed. Pelotas: EDUCAT, 2008. p. 21-40.

CETIC. (2018). TIC Educação. Disponível em: https://cetic.br/pesquisa/educacao/. Acesso em: 12 jul. 2020.

CHARTIER, R. (1997). A aventura do livro: do leitor ao navegador. Tradução de Reginaldo de Moraes. São Paulo: Editora UNESP, 1999.

"EU NÃO CONSIGO RESPIRAR!" (2020). In: Seminários Abertos PPGLI-Ufac. Disponível em: www.posletrasufac.com. Acesso em: 25 jun. 2020.

HALL, S. (1997). A centralidade da cultura: notas sobre as revoluções culturais do nosso tempo. Tradução de Ricardo Uebel, Maria Isabel Bujes e Marisa Vorraber. Educação \& Realidade. v. 22, n. 2, p. 15-46.

HONORATO-SANTOS, L.; ROSSI, C. B.; OLIVEIRA, M. A. B. A educação à distância durante a pandemia no estado do Acre: um diálogo jurídico, institucional e pedagógico, no prelo.

KIELING-SANTOS, A. J. H. (2019). Projeto Político Curricular de Letras Inglês da UFAC e a Base Nacional Comum Curricular: possíveis conexões dialógicas para o uso das tecnologias digitais. Mestrado em Letras. Programa de Pós-Graduação em Letras: Linguagem e Identidade, Ufac, Rio Branco.

KUMARAVADIVELU, B. (2006). A linguística aplicada na era da globalização. In: Moita Lopes, L. P. da; Fabrício, B. F. (orgs.), Por uma linguística aplicada indisciplinar. São Paulo, SP: Parábola, p. 129-148.

LEMKE, J. L. (2010). Letramento metamidiático: transformando significados e mídias. Tradução de Clara Dornelles. Trabalbos em Linguística Aplicada, v. 49, n. 2, p. 455-479

MARCONI, M.; LAKATOS, E. M. (2001). Metodologia do Trabalbo Científico: procedimentos básicos, pesquisa bibliográfica, projeto e relatório, publicações e trabalhos científicos. 6. ed. São Paulo: Atlas.

MARCUSCHI, L. A. (2008). Gêneros textuais no ensino de língua. In: Marcuschi, L. A., Produção Textual Análise de gêneros e compreensão. São Paulo: Parábola Editorial. p. 146-225.

MARTINI, A. (2019). Tecendo limites no Alto Rio Juruá. Curitiba: Brazil Publishing.

MINISTÉRIO DA EDUCAÇÃO, (MEC); CONSELHO NACIONAL DE EDUCAÇÃO (CNE). (2015). Resolução $n^{\circ}$ 2, de $1^{\circ}$ de julbo de 2015 do CNE/CP. Disponível em: http://portal.mec.gov.br/index.php?option=com_docman\&view=download\&ali as =136731-rcp002-15-1\&category_slug=dezembro-2019-pdf\&Itemid=30192 Acesso em: 12 jul. 2020.

MOITA LOPES, L. P. da. (2006). Uma linguística aplicada mestiça e ideológica: interrogando o campo como linguista aplicado. In: Fabrício, B. F.; Moita Lopes, L. P. da (orgs.), Por uma linguística aplicada indisciplinar. São Paulo: Parábola. p. 13-42.

OLIVEIRA-CODINHOTO, G. (2019). A imagem da escrita e o papel das tecnologias digitais de comunicação e informação em textos de professores em formação na Amazônia Sul-Ocidental. In: Komesu, F.; Assis, J. A. Práticas discursivas em letramento acadêmico: questões em estudo. v. 1: Ensaios sobre a escrita acadêmica. Belo Horizonte: Editora PUC Minas. p. 122-136.

OLIVEIRA, M. B. F. DE; SZUNDY, P. T. C. (2014). Práticas de multiletramentos na escola: por uma educação responsiva à contemporaneidade. Bakbtiniana. Revista de Estudos do Discurso, v. 9, n. 2, p. 184-205.

PAIVA, V. M. de O. e. (2013). A formação do professor para uso da tecnologia. In: Silva, K. A.; Salomão, A. C. B. (orgs.), A formação de professores de línguas: novos olhares. Campinas: Pontes, v. 2, p. 209-230.

RAJAGOPALAN, K. (2009). The Identity of "World English". In: G. R. et. al (orgs.). New challenges in language and literature. Belo Horizonte: Faculdade de Letras da UFMG, p. 97-107.

ROJO, R. (2006). Fazer Linguística Aplicada em perspectiva sócio-histórica: privação sofrida e leveza de pensamento. In: Moita Lopes, L. P. da; Fabrício, B. F. (orgs.). Por uma linguística aplicada indisciplinar. São Paulo: Parábola, p. 253-277. 
ROJO, R. (2012). Pedagogia dos multiletramentos. In: Rojo, R.; Moura, E. (orgs.), Multiletramentos na escola. São Paulo: Parábola, p. 11-31.

ROJO, R. (2013). Gêneros discursivos do Círculo de Bakhtin e multiletramentos. In: ROJO, R. (org.). Escol@ conectada: os multiletramentos e as TICS. São Paulo: Parábola, p. 13-36.

ROJO, R.; BARBOSA, J. (2015). Hipermodernidade, multiletramento e gêneros discursivos. São Paulo: Parábola Editorial.

SANTAELLA, L. (2004). Navegar no ciberespaço: o perfil cognitivo do leitor imersivo. São Paulo: Paulus.

STREET, B. (1995). Letramentos Sociais: abordagens críticas de letramento no desenvolvimento, na etnografia e na educação. Tradução de Marcos Bagno. São Paulo: Parábola Editorial, 2014.

TAPSCOTT, D. (2010). A bora da geração digital: como os jovens que cresceram usando internet estão mudando tudo, das empresas aos governos. Tradução de Lino Marcello. Rio de Janeiro: Agir Negócios.

THE NEW LONDON GROUP. (1996). A Pedagogy of Multiliteracies: Designing Social Futures. Harvard Educational Review, v. 66, n. 1, p. 60-93.

UCHÔA, J. M. S. (2014). Narrativas de professores em formação sobre a didatização de podcasts para o ensino de inglês na floresta. Tese de Doutorado em Estudos da Linguagem. Departamento de Letras, Universidade Federal do Rio Grande do Norte, Natal.

UFAC. (2018). Projeto de Reformulação do Curso de Licenciatura em Letras Inglês. (Acesso restrito. Formato digital).

UFAC. (2020). Ementário UFAC. Disponível em: https://portal.ufac.br/ementario/curriculo.action?v=394 Acesso em: 7 ago. 2020.

VOLÓCHINOV, V. (1929). Marxismo e filosofia da linguagem: problemas fundamentais do método sociológico da linguagem. Tradução de Sheila Grillo e Ekaterina Vólkova Américo. Ensaio introdutório Sheila Grillo. São Paulo: Editora 34, 2017.

Recebido: 28/1/2021

Aceito: $7 / 3 / 2021$

Publicado: $19 / 3 / 2021$ 